\title{
Long-term adherence to home mechanical ventilation: a 10-year retrospective, single-centre cohort study
}

\author{
Omar Masoud ${ }^{1 \#}$, Michelle Ramsay ${ }^{2 \#}$, Eui-Sik Suh ${ }^{2}$, Georgios Kaltsakas ${ }^{1,2}$, Shelley Srivastava ${ }^{2}$, \\ Hina Pattani' ${ }^{2}$, Philip Marino ${ }^{2}$, Patrick B. Murphy ${ }^{2}$, Nicholas Hart ${ }^{2}$, Joerg Steier ${ }^{1,2}$ \\ ${ }^{1}$ Faculty of Life Sciences and Medicine, King's College London, London, UK; ' 2 Lane Fox Unit, Guy's \& St Thomas' NHS Foundation Trust, \\ London, UK \\ Contributions: (I) Conception and design: O Masoud, M Ramsay, J Steier; (II) Administrative support: O Masoud, M Ramsay, N Hart, J Steier; (III) \\ Provision of study materials or patients: All Authors; (IV) Collection and assembly of data: O Masoud, M Ramsay, N Hart, J Steier; (V) Data analysis \\ and interpretation: O Masoud, M Ramsay, N Hart, J Steier; (VI) Manuscript writing: All authors; (VII) Final approval of manuscript: All authors. \\ \#These authors contributed equally to this work as co-first authors. \\ Correspondence to: Joerg Steier, FRCP, MD, PhD. Professor of Respiratory and Sleep Medicine, Lane Fox Unit/Sleep Disorders Centre, Westminster \\ Bridge Road, London SE1 7EH, UK. Email: Joerg.steier@kcl.ac.uk.
}

Background: Sleep-disordered breathing (SBD) can be associated with hypercapnic respiratory failure (HRF). Home Mechanical Ventilation (HMV) is the preferred long-term treatment for patients with chronic HRF. We reviewed the database of a large tertiary referral centre for HMV to study the long-term adherence to HMV in chronic hypercapnic patients.

Methods: Data on adherence and characteristics of patients who received HMV for the treatment of SDB were collected over a decade using electronic patient records. The primary outcome parameter in this study was annual non-adherence rate (patients with HMV usage of $<4$ hours/night in the service divided by the number of all new patients of the same year), secondary outcomes were patients' characteristics and reasons for low adherence. HMV adherence clinics were established to improve uptake.

Results: Two thousand and two hundred twenty-eight patients with HRF were under active follow-up on HMV at the end of the recording period. In contrast, a total of 1,900 patients had their HMV contracts terminated over the course of a decade (due to non-adherence, transfer to other services or death). Out of those, 222 patients $\{62$ [52-72] years, body-mass index, BMI 40 [35-43] kg/m², 58.1\% male, Epworth Sleepiness Scale, ESS 9 [4-15] points, 4\% oxygen desaturation index, 4\% ODI 32 [20-71] $\times$ hour $^{-1}, \mathrm{TcCO}_{2}$ $6.6[6.0-7.2] \mathrm{kPa}$ met the non-adherence criteria (nocturnal usage 0-4 hours). The annual non-adherence rate was $25.5 \%$ of all new setups in 2010, and declined to $3.4 \%$ in 2019 (relative reduction of $86 \%, \mathrm{P}<0.001$ ). Patients with Obstructive Sleep Apnoea/Obesity Hypoventilation Syndrome (58.2\%), Neuromuscular Diseases (NMD) (26.8\%) and COPD (13.6\%) accounted for most cases of this non-adherent cohort. The vast majority of the patients $(96.1 \%)$ were established on full-face masks. In $23.4 \%$ of patients, substantial weight loss $(>10 \%)$ was the most common reason for low adherence; general displeasure $(21.3 \%)$, uncontrolled symptoms (12.8\%), claustrophobia (6.7\%), mood (4.8\%) and mask intolerance (4.3\%) caused problems as well.

Conclusions: Non-adherence to HMV in patients with chronic HRF can affect significant proportions of patients. However, the non-adherent rate substantially decreases when individual treatment solutions are offered in multi-disciplinary clinics.

Keywords: Hypercapnic respiratory failure; chronic obstructive pulmonary disease (COPD); neuromuscular disease; obesity hypoventilation syndrome; non-invasive ventilation

Submitted May 22, 2020. Accepted for publication Jul 27, 2020.

doi: 10.21037/jtd-cus-2020-003

View this article at: http://dx.doi.org/10.21037/jtd-cus-2020-003

(c) Journal of Thoracic Disease. All rights reserved. 


\section{Introduction}

Sleep-disordered breathing (SDB) is common $(1,2)$, usually under-diagnosed $(3,4)$, and with increasing prevalence $(5,6)$. It can cause adverse health outcomes, resulting in a four-fold increase in all-cause-mortality (7), excessive daytime sleepiness $(1,8)$, cardiovascular incidents $(1,9)$, and cognitive decline $(10,11)$. The economic burden of SDB is considerable (12).

Continuous Positive Airway Pressure (CPAP) therapy is the treatment of choice for normocapnic SDB (13). However, Home Mechanical Ventilation (HMV) is the preferred choice for SDB that is accompanied by chronic hypercapnic respiratory failure (HRF), as it improves clinical outcomes in OSA $(9,14)$ and Obesity Hypoventilation Syndrome (15) (OSA/OHS), Neuromuscular Disease (NMD) (16) and chronic obstructive pulmonary disease (COPD) $(17,18)$.

A potential barrier to HMV therapy, similar to CPAP (19), is limited long-term adherence. Between $46 \%$ and $83 \%$ of patients on HMV may be classified as non-adherent, as defined by more than four hours of nightly usage $(20,21)$. This is important in the knowledge that other methods of treating SDB with hypercapnia do not offer the same efficacy as HMV.

With lack of alternatives to HMV, it is essential to understand the cohort of patients who are established on HMV with limited long-term adherence, and the reasons behind this. The purpose of this study was to analyse nonadherence rates in HMV users over a decade [2010-2019] and identify reasons behind low long-term uptake.

We present the following article in accordance with the STROBE reporting checklist (available at http://dx.doi. org/10.21037/jtd-cus-2020-003).

\section{Methods}

This was a retrospective, single-centre cohort study of the patient population established on HMV under the care of the Lane Fox Respiratory Unit (LFU) at Guy's and St Thomas' NHS Foundation, London, UK. The study was registered as a service evaluation (Project reference number: GSTT/2017/6984) and individual consent was not required. Patients' numbers and trends in long-term non-adherence rates were recorded from the service database. Trends in the patients' characteristics over the decade were noted.

\section{Non-adberence rate}

Long-term non-adherence was defined as less than four hours of HMV usage per night over at least one clinic follow-up period (3 months or longer), despite best efforts to support the treatment, including the offering of humidifiers, resolving mask problems and adjusting pressures, as well as personalised face-to-face multidisciplinary clinic followup appointments (including doctor, nurse and technician), leading eventually to the HMV contract being terminated. Non-adherence rate $\left(\mathrm{NAR}_{\mathrm{HMV}}\right)$ was calculated by dividing the number of patients who had their contracts terminated due to non-adherence in any given calendar year by the total number of new patients set up on HMV the same year.

\section{Outcome parameters}

The primary outcome parameter in this study was the annual non-adherence rate over the 10 -year study period. Secondary outcomes were patients' characteristics and reported reasons for long-term HMV failure.

\section{Patient cobort}

Patients under the care of the LFU who received HMV for the treatment of hypercapnic SDB between $1^{\text {st }}$ of January 2010 to $31^{\text {st }}$ of December 2019 were included if they were above the age of 16 years, both genders were included, and patients achieved satisfactory respiratory control on ventilation during the initial titration sleep study (4\%ODI $<5 \times$ hour $^{-1}$ ). Patients who required ventilation due to acute critical illness and did not have any a titration nights were excluded from the analysis, as were patients under the care of satellite units who were not directly admitted to Lane Fox Unit, or patients who failed to achieve acceptable respiratory control during the initial HMV setup.

\section{Short protocol}

Data on admission and discharge of patients and nonadherence rates were collected from the unit's monthly summaries detailing all new patients admitted, and patients discharged with the reason of discharge. The reason of discharge was then confirmed. When discharge from follow-up was due to non-adherence to HMV an extensive search of the Electronic Patient Record (EPR), E-Noting and IntelliSpace Critical Care and Anesthesia (Philips, Amsterdam, The Netherlands) and the unit's local ventilator database were initiated to obtain the most recent information on:

* Age (years); 


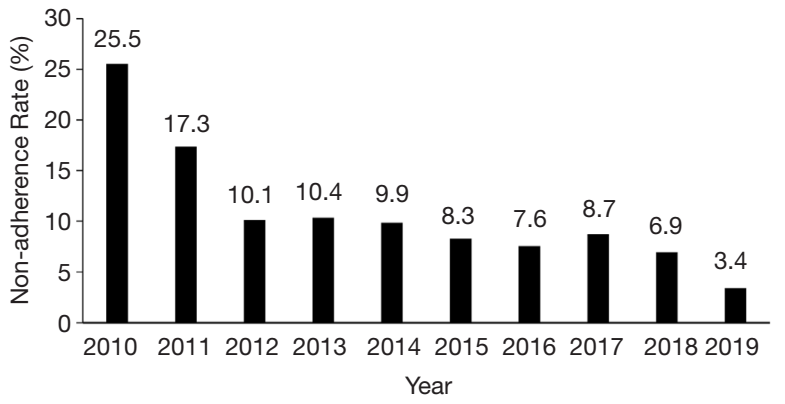

Figure 1 Proportion of non-adherent patients each year compared to all new setups on HMV and who were discharged.

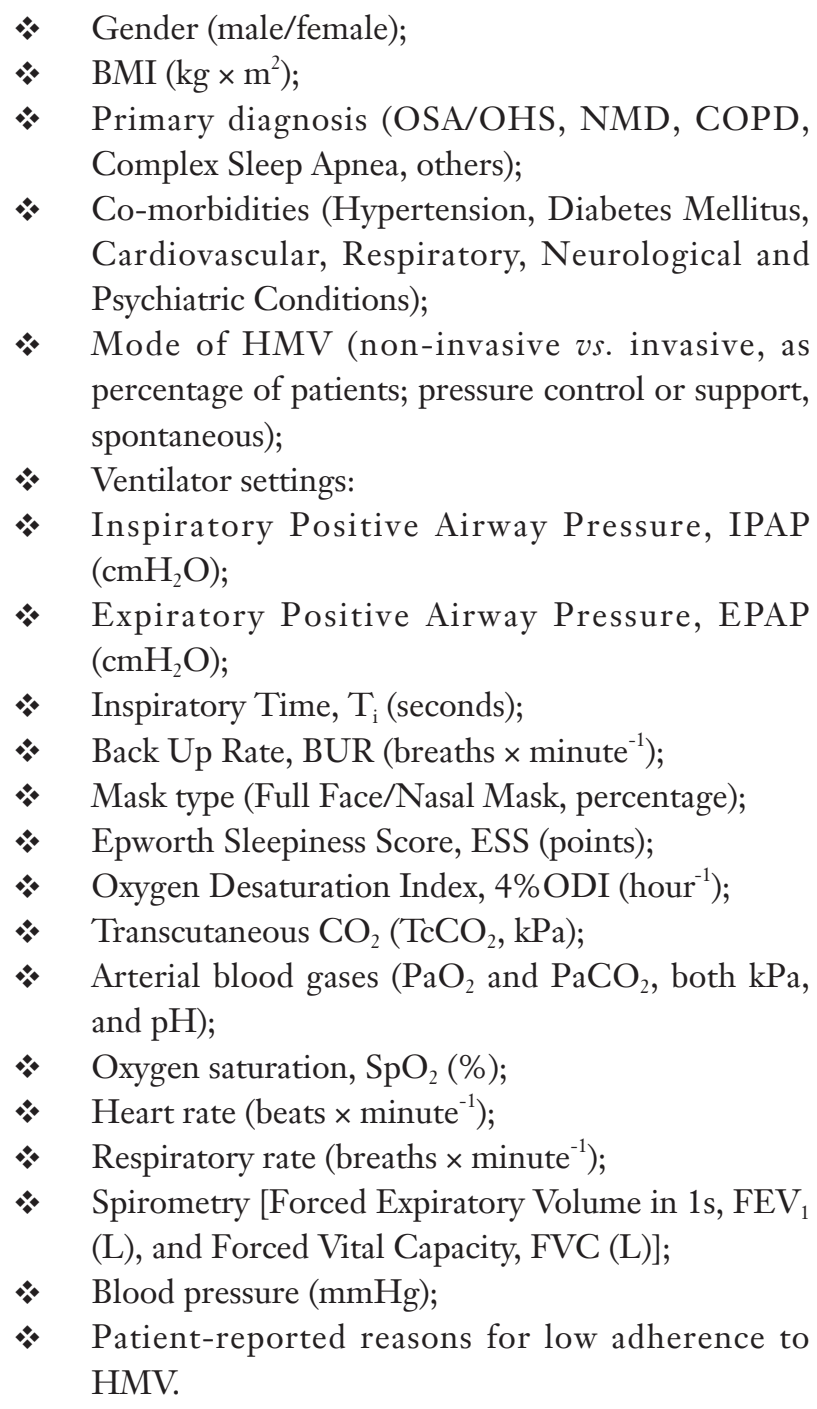

\section{Statistical analysis}

Data were collected with MS Excel 2016 Version 16.37
(Microsoft, Washington/USA) and analysed further using SPSS Version 26 (IBM, New York/USA). For ease of analysis and interpretation, the 10 -year study period was divided into three time periods, (I) 2010-2013, (II) 20142016, and (III) 2017-2019. Following the Shapiro-Wilk test for normality normally distributed data were presented as mean (standard deviation, SD), while non-normally distributed data were reported as median (interquartile range, IQR, first to third quartile). Means were compared using the Student's $t$-test for normally distributed data and Mann-Whitney U-test for non-normally distributed data. To examine trends, a one-way ANOVA test was conducted for normally distributed data, and one-way ANOVA on ranks for non-normally distributed data. For categorical data, a Pearson's Chi-squared test was used. For all tests, a level of significance was defined as $\mathrm{P}<0.05$.

\section{Results}

Two thousand and two hundred twenty-eight patients with chronic HRF were actively established on HMV at the end of the decade. Combining the number of admissions and discharges, there was an increase of 328 newly established patients on HMV in the final year only. During the recording period [2010-2019], 1,900 patients had their contracts terminated for various reasons, including nonadherence $(n=222)$, transfer to other units $(n=468)$ and death $(n=1,210)$.

\section{Demographics of non-adherent patients}

The 222 patients who met the non-adherence criteria, as defined above, were included in the analysis. The nonadherence rate $\left(\mathrm{NAR}_{\mathrm{HMV}}\right)$ decreased over the decade, from initially $25.5 \%$ in 2010 to $3.4 \%$ of patients in 2019 . This is a relative reduction of $86 \%(\mathrm{P}<0.001)$ (Figure 1). The patients were predominantly in their $6^{\text {th }}-8^{\text {th }}$ lifetime decade age 62 [52-72] years\}, obese to morbidly obese $\{$ BMI 40 [35-43] kg/ $\left.\mathrm{m}^{2}\right\}$, and included more male subjects (58.1\%). The baseline demographics did not significantly change for this cohort over the course of the decade ( $\mathrm{p}$-trend=0.65). Patients were mildly sleepy with an ESS of 9 [4-15] points. The clinical observations (heart rate, respiratory rate, systolic and diastolic blood pressure) of the entire cohort recorded at discharge following their HMV setup remained stable over the entire decade. Only oxygenation $\left(\mathrm{SpO}_{2}\right)$ at discharge showed a significant change from 94 [90-96] \% in 20102013 to 96 [93-98] \% in 2017-2019 ( $\mathrm{P}=0.04)$. The arterial 
blood gas analysis indicated chronic mild and compensated HRF $\left[\mathrm{pCO}_{2} 6.6(6.0-7.2) \mathrm{kPa}, \mathrm{pO}_{2} 9.2(1.8) \mathrm{kPa}\right.$ and $\mathrm{pH} 7.40(7.37-7.42)]$. The most common diagnosis in this cohort was OSA/OHS (58.2\%), followed by NMD (26.8\%), COPD (13.6\%) and Complex Sleep Apnea (CSA) (1.4\%); the relative proportion of the frequency of these disease groups did not change significantly during the observation period $(\mathrm{P}=0.41)$. The total group characteristics recorded an $\mathrm{FEV}_{1}$ of 1.5 (0.9-2.1) L, FVC of 2.1 (1.4-2.9) $\mathrm{L}$ and $\mathrm{FEV}_{1} / \mathrm{FVC}$ ratio of 0.77 (0.60-0.86), with the COPD subgroup having more obstructive spirometry. Subgroup analysis of the patients who had COPD, compared those who had not, also revealed that the COPD group were more hypoxic $\left[\mathrm{pO}_{2} 7.9\right.$ (1.4) vs $\mathrm{pO}_{2} 9.4$ (1.7) $\left.\mathrm{kPa} ; \mathrm{P}=0.002\right]$ and hypercapnic $\left[\mathrm{pCO}_{2} 7.5\right.$ (6.5-8.5) vs. $\mathrm{pCO}_{2} 6.2(5.5-7.1)$ $\mathrm{kPa} ; \mathrm{P}=0.001]$. They also had a lower $\mathrm{FEV}_{1}[1.2(0.7-1.5)$ vs. 1.5 (0.9-2.2) $\mathrm{L} ; \mathrm{P}=0.012]$ while there was no significant difference for the FVC between the groups $(\mathrm{P}=0.071$; Table 1).

\section{Comorbidities}

Thirty-one point five percent of the patients in the nonadherent cohort had hypertension $(31.5 \%)$, and $22.5 \%$ had type II diabetes mellitus. Other prevalent co-morbidities were of cardiovascular (19.7\%), respiratory (12.2\%), psychiatric $(15.3 \%)$ and neurological $(8.7 \%)$ cause. None of the proportions of these co-morbidities changed significantly during the observation period (Table 2).

\section{Nocturnal monitoring}

The initial nocturnal monitoring recorded a moderate amount of oxygen desaturations, the $4 \%$ oxygen desaturation index, 4\%ODI was 24 [12-47] events $\times$ hour $^{-1}$, being slightly higher in the years 2014-2016 with a $4 \%$ ODI of $32[20-71]$ events $\times$ hour $^{-1}(\mathrm{P}=0.01)$. Transcutaneous monitoring recorded the carbon dioxide levels $\left(\mathrm{tCO}_{2}\right)$ at $6.6(6.0-7.2) \mathrm{kPa}$ when asleep. Non-invasive ventilation (NIV) settings for this cohort remained similar over the observational period (p-trend=n.s.). IPAP was 22 [18-26] $\mathrm{cmH}_{2} \mathrm{O}$, EPAP was 8 [5-10] $\mathrm{cmH}_{2} \mathrm{O}$, Ti was $1.2(0.2)$ seconds, with a backup rate (BUR) of 14 [12-16] breaths $\times$ minute $^{-1}$. The patients used almost exclusively full-face masks (96.1\%; Table 1).

\section{Problems with long-term adberence to HMV}

The analysis of problems highlighted issues that contributed to limited long-term adherence. 'Uncontrolled symptoms' was named as the leading cause of limited long-term adherence by $37.3 \%$ in $2010-2013$, but this proportion decreased to $12.8 \%$ in $2017-2019(\mathrm{P}<0.001)$. A similar trend was observed with 'mask intolerance', being named by $28.4 \%$ of non-adherent patients in 2010-2013; this decreased to $4.3 \%$ in $2017-2019(\mathrm{P}<0.001)$.

In contrast, the percentage of patients who were nonadherent and reported 'general displeasure' of HMV as the primary cause rose significantly from $5.7 \%$ in 2010 2013 to $21.3 \%$ in $2017-2019(\mathrm{P}<0.001)$. In addition, the proportion of patients that stopped using HMV due to a reduction in their symptoms following substantial weight loss, either by conventional methods or bariatric surgery, increased significantly from $9.8 \%$ in $2010-2013$ to $23.4 \%$ in 2017-2019 $(\mathrm{P}<0.001)$. Other reported causes of nonadherence were 'claustrophobia' $(6.7 \%)$, not using the ventilator due to 'low mood' $(4.8 \%)$ and 'other causes' (18.7\%; Table 3).

\section{Discussion}

Over the last decade, non-adherence rates leading to a termination of HMV have dropped from about $1 / 4$ to about 1/30. The demand for HMV has significantly increased in recent years and using quality improvement projects to account for patients' specific needs can significantly improve uptake. Limited adherence to HMV is more common in milder conditions, lower symptom burden, lower carbon dioxide levels and less severe SDB, e.g., patients with OSA combined with only mildly elevated levels of $\mathrm{pCO}_{2}$. Patients who are more severely affected by chronic HRF, e.g., patients with COPD, are more likely to remain adherent to HMV. Contrary to the assumption that high HMV pressure settings cause particular adherence issues, it was the cohort of patients with lower NIV pressure settings who were more often non-adherent. However, there was a trend that less patients stopped HMV due to lack of symptom control or mask issues over the observation period, indicating better respiratory control, improved titration strategies and more acceptable devices and interfaces. Another factor that has changed over the last decade is that the number of bariatric interventions has increased substantially, with more patients returning HMV due to weight loss and resolution of their underlying SDB. 'General displeasure' of HMV, health beliefs, low mood, and claustrophobia, however, remain an unresolved problem and may require novel approaches, e.g., educational approaches and cognitive behavioural therapy, 
Table 1 Characteristics and their trends for the non-adherent patient cohort

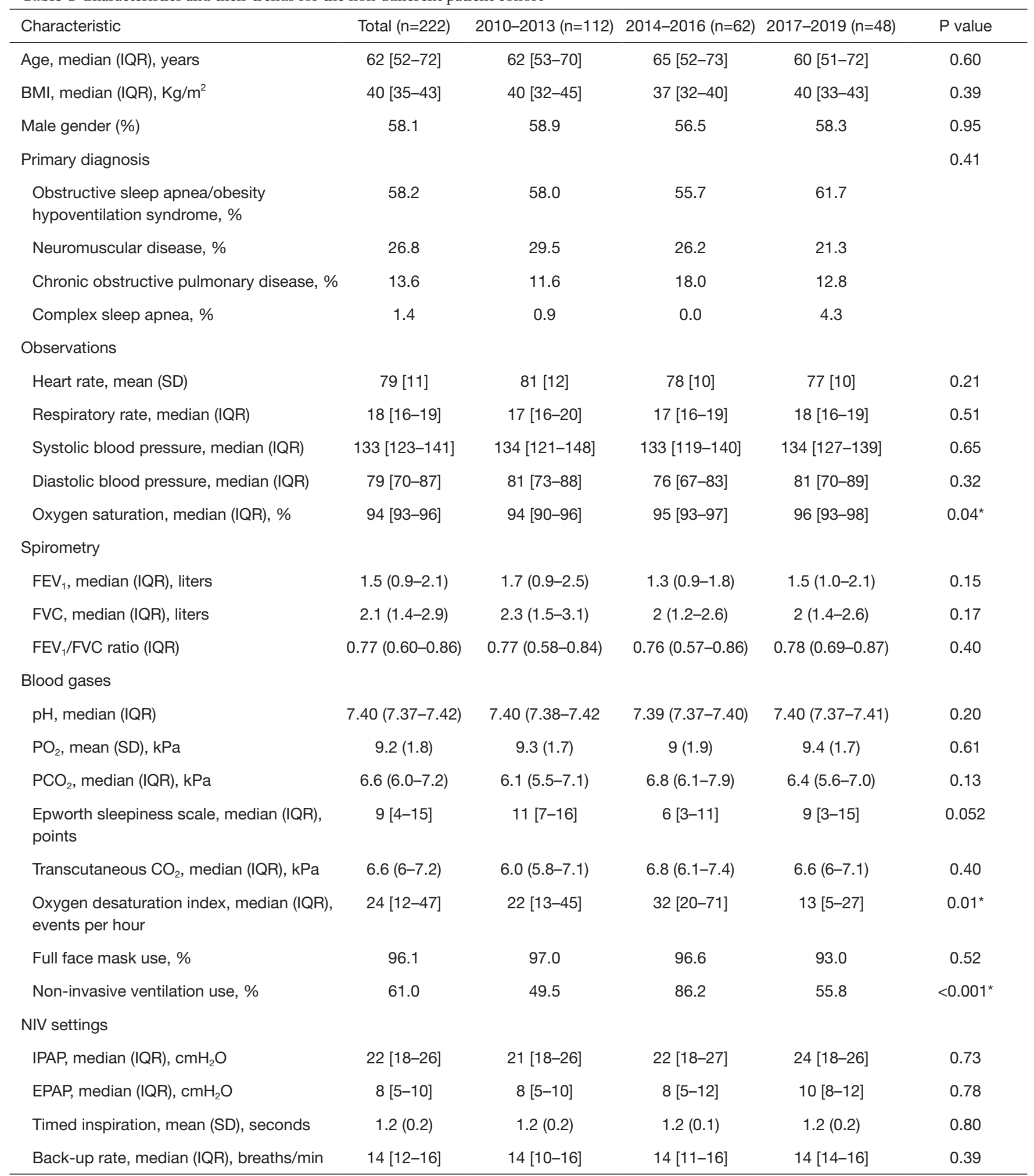

Patients who were not on NIV received CPAP therapy instead. * $\mathrm{P}<0.05$. 
Table 2 The prevalence of Co-morbidities and their trends in the non-adherent patient cohort

\begin{tabular}{|c|c|c|c|c|c|}
\hline Co-morbidity (\% patients affected) & Total $(n=222)$ & $2010-2013(n=112)$ & $2014-2016(n=62)$ & $2017-2019(n=48)$ & $P$ value for trend \\
\hline Diabetes mellitus (type II) & 22.5 & 19.1 & 22.6 & 30.4 & 0.30 \\
\hline Psychiatric & 15.3 & 10.7 & 24.2 & 14.9 & 0.06 \\
\hline Neurological & 8.7 & 7.3 & 4.8 & 17 & 0.06 \\
\hline Cardiovascular & 19.7 & 22.0 & 12.9 & 23.4 & 0.25 \\
\hline
\end{tabular}

Cardiovascular Co-morbidities included atrial fibrillation (18 patients), ischaemic heart disease (15 patients), hypercholesteremia (6 patients), dyslipidemia (2 patients) and heart failure (2 patients). Psychiatric Co-morbidities included Depression (20 patients), schizophrenia (7 patients), generalized anxiety disorder (4 patients), bipolar disorder (1 patient), personality disorder (1 patient) and agoraphobia (1 patient). Respiratory Co-morbidities included COPD in patients where it was not the primary diagnosis (12 patients), asthma (7 patients), lung cancer (3 patients), Kartagener syndrome (1 patient), chronic sinusitis (1 patient), bronchiectasis (1 patient), upper airway obstruction syndrome (1 patient) and pulmonary hypertension (1 patient). Neurological Co-morbidities in patients where it was not primary diagnosis included epilepsy (3 patients), dementia (3 patients), post-polio syndrome (2 patients), bulbar dysfunction (1 patient), quadriplegia (1 patient), Parkinson's disease (1 patient), cerebral palsy (1 patient), myasthenia gravis (1 patient), Asperger's syndrome (1 patient), autonomic dysreflexia (1 patient), cognitive impairment (1 patient), bilateral optic neuropathy (1 patient), narcolepsy (1 patient) and left-hemidiaphragm paralysis (1 patient).

Table 3 The reasons of suboptimal HMV adherence and their trends in the non-adherent patient cohort

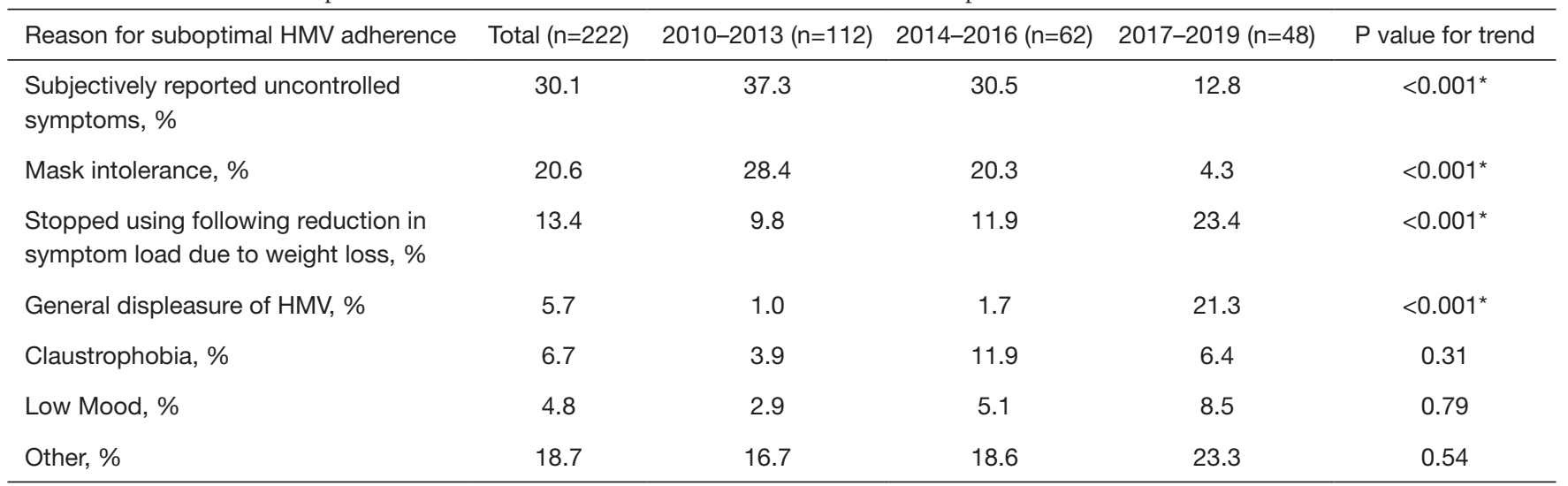

Other causes of HMV failure were air leakage (4.2\%), aerophagia (2.9\%), cognitive problems (2.4\%), excessive salivation (1.0\%), dry mouth $(2.9 \%)$, headache $(1.4 \%)$, toothache $(0.5 \%)$, anxiety $(2.4 \%)$, lack of machine mobility $(0.5 \%)$ and chronic sinusitis $(0.5 \%)$. ${ }^{*}, \mathrm{P}<0.05$.

to improve outcomes further.

\section{Clinical significance}

During the last decade, our service increased the number of Consultants over the observation period, CPAP failure clinics were established in 2014, and NIV failure clinics in 2016. The improved medical cover was combined with delivery of more structured education for patients and carers, as well as interactive CPAP/HMV adherence clinics, which might have contributed to the observed reduction in non-adherence; the following of clinical guidelines and the emergence of new evidence and protocols on the efficacy of HMV, and the development of novel technology and interfaces is likely to have further contributed.

However, the increase in the prevalence of patients with chronic HRF raises concerns. There are many reasons why we see more patients nowadays, including the obesity pandemic (22), increased awareness amongst doctors and the public (23), initiatives to screen surgical patients $(24,25)$ and patients with neuromuscular conditions (26), and an increase in availability of diagnostic tests. However, long- 
term adherence to HMV is essential, as mortality rates in chronic respiratory failure on HMV remain high (27) and deteriorate when HMV is abandoned (28).

An important factor leading to 'general displeasure' and problems with adherence are interface issues, such as facial ulcers (29) and dryness of the mouth (30), and how to manage them. Sopkova et al. (31), analysing different possible causes of non-adherence, found that the only independent predictor of compliance was mask leak. This highlights the importance of the interface and it is likely that the reduction in mask problems, as reported in this study, contributed to the reduction in non-adherence. Furthermore, there has been suggestive evidence that the use of a nasal mask, rather than a full-face interface, can further improve adherence (32).

Better symptom control, as observed in our cohort, significantly improves long-term adherence rates. Patients who experience no improvement in their symptoms while using HMV therapy are at risk of not to acknowledging the benefits of this treatment $(33,34)$. Various motivational and educational techniques, including 'framing' (19), cognitive behavioral therapy (35-37) and motivational interviewing (38), can increase patient self-efficacy and adherence in these scenarios. Furthermore, it has been shown that patients on NIV, rather than on CPAP therapy, are more tolerable of treatment with an increased adherence (39).

\section{Limitations}

This was a retrospective analysis of a service database over an entire decade, and there are challenges with retrospective datasets. However, due to the large number of patients involved the analysis contributes important information to understand the subgroup of patients who have difficulties with using long-term HMV. Besides our observational data, socio-economic and ethnic data have been shown to be predictors of adherence to HMV (40-43). However, our study was limited to the information included in patients' hospital records; we were therefore unable to report on some factors which may have influenced adherence, such as ethnicity, educational and marital status. We therefore acknowledge that there is the risk of confounding factors affecting and limiting the generalisability of our data. In addition, many patients were transferred to other hospitals following HMV initiation, and some data were inevitably lost-to-follow-up. However, these limitations reflect routine clinical practice and shine a light on how increased staffing capacity and personalised medicine, as provided in multidisciplinary CPAP/NIV adherence clinics, can make an impact on important clinical outcomes (39).

\section{Conclusions}

Non-adherence rates to HMV have steadily decreased over the past decade despite rising numbers of patients utilizing HMV. Improved diagnostics and therapeutics, patient selection, teaching and education, better staffing and increased resource allocation, as well as advanced treatment strategies have helped this trend. Targeting non-adherence in HMV improves standards of care for patients with chronic HRF, provides better resource utilization and costefficiency, and impacts on significant adverse long-term health outcomes.

\section{Acknowledgments}

The views expressed are those of the authors and not necessarily those of the NHS, the NIHR or the Department of Health.

Funding: None.

\section{Footnote}

Provenance and Peer Review: This article was commissioned by the Guest Editor (Joerg Steier) for the series " 5 th Clinical Update Sleep" published in Fournal of Thoracic Disease. The article was sent for external peer review.

Reporting Checklist: The authors have completed the STROBE reporting checklist. Available at http://dx.doi. org/10.21037/jtd-cus-2020-003

Data Sharing Statement: Available at http://dx.doi. org/10.21037/jtd-cus-2020-003

Conflicts of Interest: All authors have completed the ICMJE uniform disclosure form (available at http://dx.doi. org/10.21037/jtd-cus-2020-003). The series " $5^{\text {th }}$ Clinical Update Sleep" was commissioned by the editorial office without any funding or sponsorship. JS served as the unpaid Guest Editor of the series and serves as an unpaid editorial board member of Fournal of Thoracic Disease. JS's contributions were partially supported by the National Institute for Health Research (NIHR) Biomedical Research Centre based at Guy's and St Thomas' NHS Foundation Trust and King's College London, UK. The authors have 
no other conflicts of interest to declare.

Ethical Statement: The authors are accountable for all aspects of the work in ensuring that questions related to the accuracy or integrity of any part of the work are appropriately investigated and resolved. The study was conducted in accordance with the Declaration of Helsinki (as revised in 2013). The study was registered as a service evaluation (Project reference number: GSTT/2017/6984) and individual consent was not required.

Open Access Statement: This is an Open Access article distributed in accordance with the Creative Commons Attribution-NonCommercial-NoDerivs 4.0 International License (CC BY-NC-ND 4.0), which permits the noncommercial replication and distribution of the article with the strict proviso that no changes or edits are made and the original work is properly cited (including links to both the formal publication through the relevant DOI and the license). See: https://creativecommons.org/licenses/by-nc-nd/4.0/.

\section{References}

1. Heinzer R, Vat S, Marques-Vidal P, et al. Prevalence of Sleep-Disordered Breathing in the General Population: The HypnoLaus Study. Lancet Respiratory Medicine 2015;3:310-8.

2. Young T, Palta M, Dempsey J, et al. The Occurrence of Sleep-Disordered Breathing among Middle-Aged Adults. N Engl J Med 1993;328:1230-5.

3. Young T, Peppard PE, Gottlieb D. Epidemiology of Obstructive Sleep Apnea A Population Health Perspective. Am J Respir Crit Care Med 2002;165:1217-39.

4. Foldvary-Schaefer NR, Waters TE. Sleep-Disordered Breathing. Continuum (Minneapolis/MN) 2017;23:1093-116.

5. Jordan AS, Mc Sharry DG, Malhotra A. Adult obstructive sleep apnoea. Lancet 2014;383:736-47.

6. Hamilton GS, Joosten SA. Obstructive sleep apnoea and obesity. Aust Fam Physician 2017;46:460-3.

7. Marshall NS, Wong KK, Cullen SR, et al. Sleep Apnea and 20-year Follow-up for All-cause Mortality, Stroke, and Cancer Incidence and Mortality in the Busselton Health Study cohort. J Clin Sleep Med 2014;10:355-62.

8. Malhotra A, White DP. Obstructive Sleep Apnoea. Lancet 2002;360:237-45.

9. Marin JM, Carrizo SJ. Mortality in Obstructive Sleep Apnea. Sleep Medicine Clinics 2007;2:593-601.

10. Leng Y, McEvoy CT, Allen IE, et al. Association of Sleep-
Disordered Breathing With Cognitive Function and Risk of Cognitive Impairment: A Systematic Review and Metaanalysis. JAMA Neurol 2017;74:1237-45.

11. Shi L, Chen SJ, Ma MY, et al. Sleep Disturbances Increase the Risk of Dementia: A Systematic Review and MetaAnalysis. Sleep Med Rev 2018;40:4-16.

12. Hillman D, Mitchell S, Streatfeild J, et al. The Economic Cost of Inadequate Sleep. Sleep 2018;41:zsy083.

13. Sullivan CE, Issa FG. Berthon-Jones M, et al. Reversal of obstructive sleep apnoea by continuous positive airway pressure applied through the nares. Lancet 1981;1:862-5.

14. Iftikhar IH, Bittencourt L, Youngstedt SD, et al. Comparative Efficacy of CPAP, Mads, Exercise-Training, and Dietary Weight Loss for Sleep Apnea: A Network Meta-Analysis. Sleep Med 2017;30:7-14.

15. Onofri A, Patout M, Kaltsakas G, et al. Neural respiratory drive and cardiac function in patients with obesity hypoventilation syndrome following initiation of noninvasive ventilation. J Thorac Dis 2018;10:S135-43.

16. Bourke SC, Tomlinson M, Williams TL, et al. Effects of Non-Invasive Ventilation on Survival and Quality of Life in Patients with Amyotrophic Lateral Sclerosis: A Randomised Controlled Trial. Lancet Neurol 2006;5:140-7.

17. Murphy PB, Rehal S, Arbane G, et al. Effect of home noninvasive ventilation with oxygen therapy vs oxygen therapy alone on hospital readmission or death after an acute COPD exacerbation: a randomized controlled clinical trial. JAMA 2017;317:2177-86.

18. Köhnlein T, Windisch W, Köhler D, et al. Non-invasive Positive Pressure Ventilation for the Treatment of Severe Stable Chronic Obstructive Pulmonary Disease: A Prospective, Multicentre, Randomised, Controlled Clinical Trial. Lancet Respir Med 2014;2:698-705.

19. Pengo MF, Czaban M, Berry MP, et al. The Effect of Positive and Negative Message Framing on Short Term Continuous Positive Airway Pressure Compliance in Patients with Obstructive Sleep Apnea. J Thorac Dis 2018;10:S160-9.

20. Weaver TE, Grunstein RR. Adherence to Continuous Positive Airway Pressure Therapy: The Challenge to Effective Treatment. Proc Am Thorac Soc 2008;5:173-8.

21. DiMatteo MR. Variations in Patients' Adherence to Medical Recommendations: A Quantitative Review of 50 Years of Research. Med Care 2004;42:200-9.

22. Saklayen MG. The Global Epidemic of the Metabolic Syndrome. Curr Hypertens Rep 2018;20:12.

23. Robbins R, Senathirajah Y, Williams NJ, et al. Developing a Tailored Website for Promoting Awareness 
about Obstructive Sleep Apnea (OSA) Among Blacks in Community-Based Settings. Health Commun 2019;34:567-75.

24. Lakdawala L, Dickey B, Alrawashdeh MJ. Obstructive Sleep Apnea Screening Among Surgical Patients: A Quality Improvement Project. J Perianesth Nurs 2018;33:814-21.

25. Reed K, Pengo MF, Steier J. Screening for sleepdisordered breathing in a bariatric population. J Thorac Dis 2016;8:268-75.

26. Steier J, Jolley CJ, Seymour J, et al. Screening for sleepdisordered breathing in neuromuscular disease using a questionnaire for symptoms associated with diaphragm paralysis. Eur Respir J 2011;37:400-5.

27. Schwarz EI, Mackie M, Weston N, et al. Time-todeath in chronic respiratory failure on home mechanical ventilation: A cohort study. Respir Med 2020;162:105877.

28. Kreivi HR, Itaeluoma T, Bachour A. Effect of ventilation therapy on mortality rate among obesity hypoventilation syndrome and obstructive sleep apnoea patients. ERJ Open Res 2020;6:00101-2019.

29. Alqahtani JS, AlAhmari MD. Evidence Based Synthesis for Prevention of Noninvasive Ventilation Related Facial Pressure Ulcers. Saudi Med J 2018;39:443-52.

30. Esquinas Rodriguez AM, Scala R, Soroksky A, et al. Clinical review: humidifiers during non-invasive ventilation--key topics and practical implications. Crit Care 2012;16:203.

31. Sopkova Z, Dorkova Z, Tkacova R. Predictors of Compliance with Continuous Positive Airway Pressure Treatment in Patients with Obstructive Sleep Apnea and Metabolic Syndrome. Wien Klin Wochenschr 2009; 121:398-404.

32. Mortimore IL, Whittle AT, Douglas NJ. Comparison of Nose and Face Mask CPAP Therapy for Sleep Apnoea. Thorax 1998;53:290-2.

33. Baron KG, Berg CA, Czajkowski LA, et al. Self-efficacy Contributes to Individual Differences in Subjective Improvements Using CPAP. Sleep Breath 2011;15:599-606.
34. Sawyer AM, Canamucio A, Moriarty H, et al. Patient Perception, Preference and Participation. Do cognitive perceptions influence CPAP use? Patient Educ Couns 2011;85:85-91.

35. Bakker JP, Wang R, Weng J, et al. Motivational Enhancement for Increasing Adherence to CPAP: A Randomized Controlled Trial. Chest 2016;150:337-45.

36. Lai AYK, Fong DYT, Lam JCM, et al. The Efficacy of a Brief Motivational Enhancement Education Program on CPAP Adherence in OSA: A Randomized Controlled Trial. Chest 2014;146:600-10.

37. Richards D, Bartlett DJ, Wong K, et al. Increased Adherence to CPAP With a Group Cognitive Behavioral Treatment Intervention: A Randomized Trial. Sleep 2007;30:635-40.

38. Olsen S, Smith SS, Oei TPS, et al. Motivational Interviewing (MINT) Improves Continuous Positive Airway Pressure (CPAP) Acceptance and Adherence: A Randomized Controlled Trial. J Consult Clin Psychol 2012;80:151-63.

39. Ishak A, Ramsay M, Hart N, et al. BPAP is an effective second-line therapy for obese patients with OSA failing regular CPAP: A prospective observational cohort study. Respirology 2020;25:443-8.

40. Stepnowsky CJ, Marler MR, Joe Palau J, et al. Socialcognitive correlates of CPAP adherence in experienced users. Sleep Med 2006;7:350-6.

41. Platt AB, Field SH, Asch DA, et al. Neighborhood of residence is associated with daily adherence to CPAP therapy. Sleep 2009;32:799-806.

42. Bakker JP, O'Keeffe KM, Neill AM, et al. Ethnic disparities in CPAP adherence in New Zealand: effects of socioeconomic status, health literacy and self-efficacy. Sleep 2011;34:1595-603.

43. Billings ME, Auckley D, Benca R, et al. Race and residential socioeconomics as predictors of CPAP adherence. Sleep 2011;34:1653-8.
Cite this article as: Masoud O, Ramsay M, Suh ES, Kaltsakas G, Srivastava S, Pattani H, Marino P, Murphy PB, Hart N, Steier J. Long-term adherence to home mechanical ventilation: a 10-year retrospective, single-centre cohort study. J Thorac Dis 2020;12(Suppl 2):S120-S128. doi: 10.21037/jtd-cus-2020-003 